\title{
Student and faculty perspectives on Laboratory Based Learning (LBL) sessions in Physiology
}

\author{
Asha Vashe ${ }^{1}$, Reem Rachel Abraham ${ }^{1}$, Sharmila Torke ${ }^{1}$, \\ Vinod Pallath ${ }^{2}$, Asha Kamath ${ }^{3}$
}

\begin{abstract}
Objective: To explore students' and faculty members' perspectives regarding LBL sessions-the gaps/pitfalls- to explore possibilities for improvement.

Method: Two sets of questionnaires, one each for students and faculty members were developed and administered to the students of first year MBBS $(n=113)$ and Faculty members of physiology department ( $n=13$ ) of MMMC, Manipal. Both questionnaires had closed-ended questions (no negative statements) inviting responses in the form of Likert scale. Open-ended questions were included in the questionnaire distributed to faculty members. Quantitative analysis was done using SPSS version 16.

Results: Students agreed to all items, with a median score of 4 . Students' responses clearly indicated that, in general, they were satisfied with conduction of LBL sessions in physiology, while, faculty members concurred with them with a median score of 4 for items other than student related and expressed that current LBL sessions were adequate for MBBS curriculum. Faculty members were of the opinion that students need to practice more in LBL sessions. They also suggested inclusion of additional teaching aids in LBL sessions.
\end{abstract}

Conclusion: Majority of students and faculty members were satisfied with the content and methodology employed in the current laboratory based sessions in physiology. Some of the suggestions given by students and faculty members could be easily implemented for improving the process, while others require additional infrastructure and logistic support.

Keywords: Physiology practical, medical education, undergraduate curriculum, student, teacher

\section{Introduction}

Basic sciences play an essential role in medical education. This is emphasized by the fact that most clinical specialties thrive on and live by the conceptual mechanisms and theories introduced in pre-clinical courses (Wilson et al, 2009). A good knowledge of basic science gives us the tools we need to critically appraise information all of which translates into better patient care (Donnel, 2006). Physiology is one of the important subjects from basic science

\footnotetext{
${ }^{1}$ Department of Physiology

${ }^{2}$ Department of Microbiology,

Melaka Manipal Medical College (Manipal Campus),

Manipal, Karnataka, India

${ }^{3}$ Department of Community Medicine,

Kasturba Medical College, Manipal, Karnataka, India.

Corresponding author:

Dr. Asha Vashe,

Department of Physiology, Melaka Manipal Medical College (Manipal Campus), Manipal University, Manipal- 576 104, Karnataka, India

Email:drashabhat@gmail.com
}

that deals with health and explains the function and control of systems; in addition, it forms normal baseline for the study of abnormal function in medicine (Caglayan, 1994). Physiology is included in the first year curriculum of undergraduate medical education. Laboratory Based Learning (LBL) session, which is a part of physiology curriculum, provide students an opportunity to have hands on experience and also help them understand the concepts better through active mode of learning, enhancing student learning and performance (Dantas \& Kemm, 2008; Rao \& Dicarlo, 2001). "Tell me, I will forget, Show me I may remember, allow me to do it, I will understand" goes the Chinese proverb, which clearly explains the importance of LBL. Students generally enjoy laboratory based exercises and involve themselves more compared to general lectures (Crocker et al, 2008). Laboratory based form of learning also helps them to develop team spirit (Bates et al n.d.; Quinn n.d.). LBL sessions reinforce the 
theoretical concepts in addition to developing practical skills, improve the maturity level and common-sense to handle unexpected events, develop keen observation capability and analyses data scientifically (Bates et al n.d.; Quinn n.d.; Cohen, 1994). Also, for a medical student, knowledge of practical physiology is helpful to understand the pathophysiology of diseases, to explain manifestation of diseases, to provide physiological basis for the diagnosis and treatment of diseases (Pal \& Pal, 2001).

Melaka Manipal Medical College (MMMC), Manipal Campus, offers 5 years of undergraduate, Bachelor of Medicine and Bachelor of Surgery (MBBS) program, which is an intense academic program. Basic science subjects are taught in the first year, which include anatomy, physiology and biochemistry. The first year curriculum is divided in to four blocks. Block 1 includes basic concepts, skin, muscle, bones, joints and blood. Block 2 includes cardiovascular system, respiratory system, gastrointestinal tract, nutrition and hepatobiliary system. Block 3 includes the endocrine, reproduction, kidney and electrolytes. Block 4 includes the central nervous system, special senses and molecular biology. The duration of each block is ten weeks. In physiology all four blocks have LBL sessions which consist of both demonstration and hands-on experiments. One slot of two hours duration per week is devoted for LBL sessions. An established set of procedures and practices are followed while executing laboratory sessions. The laboratory sessions begin with an introduction to the experiment followed by demonstrations by faculty members before allowing students to conduct experiments. Faculty members continue to supervise the session for which an adequate student teacher ratio is maintained. Students have to maintain a laboratory journal, which provides necessary instructions for conducting experiments. Also, it helps them to record their observations from the experiments. In addition, it has a set of questions related to the experiment, equipments used, and allied concepts for which students have to find and record the answers. The laboratory journal carries $20 \%$ of marks in the practical examinations. Practical examination is conducted at the end of every block, in addition to theory examinations. In the first and third blocks, practical examination is in the form of Computer Assisted Objective Structured Practical Examination (COSPE) and in the second and fourth blocks it is in the form of Objective Structured Practical Examination (OSPE) which includes two performance stations, wherein students are required to perform the experiment in front of the examiner.

With the intention of enhancing student learning, LBL sessions were included in physiology curriculum at MMMC, Manipal campus, Manipal University. In order for LBL sessions to be effective, students need to participate with more interest and involvement. We believe, they are involved better if a conducive environment for conduction of experiment and learning is provided. Therefore, the objective of the present study was to explore students' and faculty members' perspectives regarding LBL sessions - the gaps/pitfalls - so as to explore possibilities for improvement.

\section{Method}

The present study was conducted in the Department of Physiology, MMMC, Manipal. As the students and faculty members are the key stakeholders, perceptions of both were considered. Two sets of questionnaires, one each for students and faculty members were developed and administered. The questionnaire for students contained two sections. The first section consisted of fifteen closed-ended items, to which they had to respond on a Likert scale. (Strongly disagree $=1$, strongly agree $=$ $5)$. The second section was comments/ suggestions. The questionnaire was administered to first year MBBS students $(n=113)$.

The questionnaire for faculty members $(n=13)$ had three sections. The first section consisted of 8 closed-ended questions, to which they had to respond on a Likert scale ( $1=$ strongly disagree and $5=$ strongly agree). The second section consisted of three open-ended questions intended to generate narrative comments, while, the third section invited comments / suggestions.

Content validity of the questionnaires was done by experts in physiology and medical education. Cronbach's alpha of the questionnaire developed for the students was 0.824 , whereas it could not be calculated for the questionnaire developed for faculty members since the sample size was too small ( $n=13$ ). Quantitative data was analyzed using SPSS version 16 and reported as frequency and percentage. As the data of the Likert scale response did not follow normal distribution, median and interquartile range was used to represent the data. 


\section{Results}

The response rate was $100 \%$. As shown in Table-1, students appreciated current conduct of LBL sessions with a median score of 4 for all items. The data clearly showed that $83 \%$ of the students were interested in physiology practicals. While $90 \%$ of the students agreed that physiology practicals increased the level of understanding of the subject and $88 \%$ considered that hands on experiments were better in understanding concepts than demonstration. It was worth noting that $89 \%$ think that the experiments included in the physiology curriculum were relevant to the future. As far as student to teacher ratio was concerned, $65 \%$ of the students agreed for the current ratio. Percentage of marks allotted for LBL was considered appropriate by $74 \%$ of the students while, $76 \%$ opined that the method of conducting practical examination was appropriate. Some other comments given by the students were 'practical classes were useful, helpful for the future, enjoyable, design and conducts of LBL sessions were pretty good'.

Analysis of performance of block practical examination scores substantiates the validity of the responses of students. At MMMC, Manipal, scores above or equal to $75 \%$ is declared as distinction, while below $50 \%$ falls in fail category. The rest are declared as pass. The performance of students is shown in Figure 1. In the first and second blocks $98 \%$ of the students passed. Only $2 \%$ of the students failed. In the third and fourth blocks the result was $100 \%$. In all the four blocks the percentage of students secured distinction was above $50 \%$. Average percentage of the students who scored distinction in all the four blocks was an impressive $64 \%$.

Faculty members agreed with a median score of 4 for items other than student related. All of them agreed that hands on experiments were better for understanding physiology than demonstration. As shown in the Table-2, 69\% of the faculty members felt that the current LBL was adequate for physiology course for MBBS curriculum, while, 54\% indicated that the objectives with which laboratory sessions were included in the curriculum were properly met. Only $31 \%$ of them mentioned that students consider practicals seriously. Also only $39 \%$ agreed that students are utilizing the time available in the laboratory effectively.
For the first open ended question 'What measures could be taken for effective utilization of the available time in the laboratory by students', faculty members stated that students should be engaged throughout the practical class by repeating the experiments, or asking questions about previous classes or by conducting mock tests. They felt that students should demonstrate the experiment in-front of the faculty member before leaving the laboratory, and get their observation book signed by the teacher. They indicated that video clips related to the experiment could be made use of.

For the second question 'What can be done to enhance the level of interest among students in laboratory sessions', faculty members expressed that experiments could be linked to clinical scenarios, some common cases like paralysis could be discussed to emphasize the importance of the experiments such as reflexes, digital way of learning can be introduced such as use of electronic stethoscope. They were of the opinion that audio-visuals of clinical examination can enhance interest among students.

The third question asked to the faculty members was 'What steps could be taken to motivate students to participate more effectively in LBL sessions'. They mentioned that implementation of 'assessment driven learning' would motivate students to participate more effectively in the LBL sessions. It could be in the form of small tests during the practical hours and the scores obtained by students could be included in the internal assessment. They felt that after each session randomly some students could be selected and asked to demonstrate what they have learnt in the session (experiment).

\section{Discussion}

As students are the best judges for assessing effectiveness of LBL sessions (Lata \& Walia, 2010; Prayoonwong \& Nimnuan, 2010), perception of students about the same was obtained through questionnaire. As the design and conduct of LBL was done by faculty members, their perception and suggestions were sought through a separate questionnaire. Students' responses clearly indicated that, in general, they were satisfied with conduction of LBL sessions in physiology. It is important to note that, faculty members concurred with them and expressed that current LBL sessions were adequate for MBBS curriculum. 
Table 1: Responses of students to the questionnaire $(n=113)$

\begin{tabular}{|c|c|c|c|c|c|c|c|}
\hline \multirow[b]{2}{*}{ No. } & \multirow[b]{2}{*}{ Questions } & \multicolumn{6}{|c|}{ Frequency and Percentage } \\
\hline & & $\begin{array}{l}\text { Median } \\
\text { Inter } \\
\text { Quartile } \\
\text { range }\end{array}$ & $\begin{array}{l}\text { Strongly } \\
\text { Agree }\end{array}$ & Agree & Uncertain & Disagree & $\begin{array}{l}\text { Strongly } \\
\text { disagree }\end{array}$ \\
\hline \multirow[t]{2}{*}{1} & \multirow{2}{*}{$\begin{array}{l}\text { Physiology experiments are } \\
\text { interesting enough }\end{array}$} & 4 & 18 & 76 & 14 & 3 & 2 \\
\hline & & $(4-4)$ & $15.9 \%$ & $67.3 \%$ & $12.4 \%$ & $2.7 \%$ & $1.8 \%$ \\
\hline \multirow[t]{2}{*}{2} & \multirow{2}{*}{$\begin{array}{l}\text { Experiments are closely related to the } \\
\text { topics studied in theory }\end{array}$} & 4 & 31 & 71 & 8 & 3 & 0 \\
\hline & & $(5-4)$ & $27.4 \%$ & $62.8 \%$ & $7.1 \%$ & $2.7 \%$ & 0 \\
\hline \multirow[t]{2}{*}{3} & \multirow{2}{*}{$\begin{array}{l}\text { Experiments included in the } \\
\text { laboratory sessions increase the level } \\
\text { of understanding of the subject }\end{array}$} & 4 & 31 & 71 & 10 & 0 & 1 \\
\hline & & $(5-4)$ & $27.4 \%$ & $62.8 \%$ & $8.8 \%$ & 0 & $0.9 \%$ \\
\hline \multirow[t]{2}{*}{4} & \multirow{2}{*}{$\begin{array}{l}\text { Understanding of the physiological } \\
\text { concepts is better using hands on } \\
\text { experiments compared to } \\
\text { demonstration }\end{array}$} & 4 & 53 & 46 & 12 & 1 & 1 \\
\hline & & $(5-4)$ & $46.9 \%$ & $40.7 \%$ & $10.6 \%$ & $0.9 \%$ & $0.9 \%$ \\
\hline \multirow[t]{2}{*}{5} & \multirow{2}{*}{$\begin{array}{l}\text { There is enough scope for me to } \\
\text { actively participate in the laboratory } \\
\text { sessions }\end{array}$} & 4 & 11 & 68 & 24 & 9 & 1 \\
\hline & & $(4-3)$ & $9.7 \%$ & $60.2 \%$ & $21.2 \%$ & $8 \%$ & $0.9 \%$ \\
\hline \multirow[t]{2}{*}{6} & \multirow{2}{*}{$\begin{array}{l}\text { I consider the practical sessions } \\
\text { seriously }\end{array}$} & 4 & 25 & 67 & 20 & 1 & 0 \\
\hline & & $(4-4)$ & $22.1 \%$ & $59.3 \%$ & $17.7 \%$ & $0.9 \%$ & 0 \\
\hline \multirow[t]{2}{*}{7} & \multirow{2}{*}{$\begin{array}{l}\text { Time allotted for the laboratory } \\
\text { experiments is adequate }\end{array}$} & 4 & 31 & 61 & 14 & 6 & 1 \\
\hline & & $(5-4)$ & $27.4 \%$ & $54 \%$ & $12.4 \%$ & $5.3 \%$ & $0.9 \%$ \\
\hline \multirow[t]{2}{*}{8} & \multirow{2}{*}{$\begin{array}{l}\text { Experiments are relevant to my future } \\
\text { career }\end{array}$} & 4 & 50 & 51 & 10 & 0 & 2 \\
\hline & & $(5-4)$ & $44.2 \%$ & $45.1 \%$ & $8.8 \%$ & 0 & $1.8 \%$ \\
\hline \multirow[t]{2}{*}{9} & \multirow{2}{*}{$\begin{array}{l}\text { Instructions given by the faculty about } \\
\text { the experiments during the laboratory } \\
\text { sessions are adequate }\end{array}$} & 4 & 21 & 66 & 21 & 2 & 3 \\
\hline & & $(4-4)$ & $18.6 \%$ & $58.4 \%$ & $18.6 \%$ & $1.8 \%$ & $2.7 \%$ \\
\hline \multirow[t]{2}{*}{10} & \multirow{2}{*}{$\begin{array}{l}\text { The faculty to the student ratio in the } \\
\text { laboratory is adequate }\end{array}$} & 4 & 15 & 58 & 30 & 5 & 5 \\
\hline & & $(4-3)$ & $13.3 \%$ & $51.3 \%$ & $26.5 \%$ & $4.4 \%$ & $4.4 \%$ \\
\hline 11 & Writing the details of the experiments & 4 & 22 & 61 & 22 & 6 & 2 \\
\hline & $\begin{array}{l}\text { in the record book helps me to } \\
\text { improve the understanding of the } \\
\text { experiment }\end{array}$ & $(4-3)$ & $19.5 \%$ & $54 \%$ & $19.5 \%$ & $5.3 \%$ & $1.8 \%$ \\
\hline & Writing the details of the experiments & 4 & 24 & 60 & 26 & 2 & 1 \\
\hline 12 & $\begin{array}{l}\text { In the record book gives me scope for } \\
\text { self learning }\end{array}$ & $(4-3)$ & $21.2 \%$ & $53.1 \%$ & $23 \%$ & $1.8 \%$ & $0.9 \%$ \\
\hline & Marks allotted for the practical & 4 & 14 & 70 & 19 & 6 & 4 \\
\hline 13 & $\begin{array}{l}\text { component of the physiology block } \\
\text { examination is appropriate }\end{array}$ & $(4-3)$ & $12.4 \%$ & $61.9 \%$ & $16.8 \%$ & $5.3 \%$ & $3.5 \%$ \\
\hline & The method of practical examinations & 4 & 19 & 67 & 20 & 5 & 2 \\
\hline 14 & $\begin{array}{l}\text { (COSPE in block } 1 \& 3 \text {, OSPE }+2 \\
\text { performance exercises in block } 2 \& 4 \text { ) } \\
\text { is appropriate }\end{array}$ & $(4-4)$ & $16.8 \%$ & $59.3 \%$ & $17.7 \%$ & $4.4 \%$ & $1.8 \%$ \\
\hline 15 & Assessment of the practical & 4 & 15 & 72 & 18 & 6 & 2 \\
\hline (1) & component in physiology is fair & $(4-4)$ & $13.3 \%$ & $63.7 \%$ & $15.9 \%$ & $5.3 \%$ & $1.8 \%$ \\
\hline
\end{tabular}


Table 2: Responses given by faculty members $(n=13)$

\begin{tabular}{|c|c|c|c|c|c|c|c|}
\hline \multirow[b]{2}{*}{ No. } & \multirow[b]{2}{*}{ Questions } & \multicolumn{6}{|c|}{ Frequency and Percentage } \\
\hline & & $\begin{array}{l}\text { Median } \\
\text { Inter } \\
\text { Quartile } \\
\text { range }\end{array}$ & $\begin{array}{l}\text { Strongly } \\
\text { Agree }\end{array}$ & Agree & Uncertain & Disagree & $\begin{array}{l}\text { Strongly } \\
\text { disagree }\end{array}$ \\
\hline \multirow{2}{*}{1} & \multirow{2}{*}{$\begin{array}{l}\text { Current laboratory based learning is } \\
\text { adequate for the MBBS physiology } \\
\text { course }\end{array}$} & 4 & 3 & 6 & 1 & 2 & 1 \\
\hline & & $(4-2.5)$ & $23.1 \%$ & $46.1 \%$ & $7.7 \%$ & $15.4 \%$ & $7.7 \%$ \\
\hline \multirow[b]{2}{*}{2} & \multirow{2}{*}{$\begin{array}{l}\text { Understanding physiology is better } \\
\text { using hands on experiments } \\
\text { compared to demonstration }\end{array}$} & 5 & 10 & 3 & 0 & 0 & 0 \\
\hline & & $(5-4.5)$ & $76.9 \%$ & $23.1 \%$ & 0 & 0 & 0 \\
\hline \multirow{2}{*}{3} & \multirow{2}{*}{$\begin{array}{l}\text { Students consider the practical } \\
\text { sessions seriously }\end{array}$} & 2 & 0 & 4 & 1 & 7 & 1 \\
\hline & & $(4-2)$ & 0 & $30.8 \%$ & $7.7 \%$ & $53.8 \%$ & $7.7 \%$ \\
\hline \multirow{2}{*}{4} & \multirow{2}{*}{$\begin{array}{l}\text { The faculty to student ratio in the } \\
\text { laboratory is adequate }\end{array}$} & 4 & 5 & 6 & 1 & 1 & 0 \\
\hline & & $(5-4)$ & $38.5 \%$ & $46.2 \%$ & $7.7 \%$ & $7.7 \%$ & 0 \\
\hline \multirow{2}{*}{5} & \multirow{2}{*}{$\begin{array}{l}\text { The objectives with which the } \\
\text { laboratory sessions are included in } \\
\text { the curriculum are properly met }\end{array}$} & 4 & 3 & 4 & 4 & 2 & 0 \\
\hline & & $(4-3)$ & $23.1 \%$ & $30.8 \%$ & $30.8 \%$ & $15.4 \%$ & 0 \\
\hline \multirow[b]{2}{*}{6} & \multirow{2}{*}{$\begin{array}{l}\text { Marks allotted for the practical } \\
\text { component of physiology block } \\
\text { examination is appropriate }\end{array}$} & 4 & 2 & 7 & 3 & 1 & 0 \\
\hline & & $(4-3)$ & $15.4 \%$ & $53.8 \%$ & $23.1 \%$ & $7.7 \%$ & 0 \\
\hline \multirow[b]{2}{*}{7} & \multirow{2}{*}{$\begin{array}{l}\text { The method of practical examinations } \\
\text { (COSPE in block } 1 \& 3 \text {, OSPE }+2 \\
\text { performance exercises in block } 2 \& 4 \text { ) } \\
\text { is appropriate }\end{array}$} & 4 & 1 & 6 & 2 & 4 & 0 \\
\hline & & $(4-2)$ & $7.7 \%$ & $46.2 \%$ & $15.4 \%$ & $30.8 \%$ & 0 \\
\hline \multirow{2}{*}{8} & \multirow{2}{*}{$\begin{array}{l}\text { Students are utilizing the available } \\
\text { time in laboratory effectively }\end{array}$} & 2 & 0 & 5 & 0 & 5 & 3 \\
\hline & & $(4-1.5)$ & 0 & $38.5 \%$ & 0 & $38.5 \%$ & $23.1 \%$ \\
\hline
\end{tabular}

It was encouraging to know from their response that physiology experiments were interesting for students. Comments like "I enjoy physiology practicals" and "there should be more experiments", indicate their positive attitude towards LBL sessions. Also, they agreed that, they could understand the subject better through LBL sessions. Students' inputs also indicated that they considered LBL sessions seriously. The performance of the students in block practical examinations supports this. The suggestions like "Increase the time allotted for the practical sessions" showed that they felt LBL sessions were useful. But the faculty members' opinion differed in this case. The reason may be that the expectations of the teacher about their students may be higher. It may also be due to the fact that the experience of teachers demands additional efforts by students to learn the skills. The teachers may also have come to the conclusion that students exhibit lower level of involvement because they did not utilize the time well in laboratory sessions. This was supported by their response to the question 'students utilize the time available in the lab effectively'. Teachers disagreed with the median score of 2 . Only $35 \%$ of the faculty members agreed. This was also emphasized by the fact that only $54 \%$ of faculty members agreed that objectives of LBL sessions were properly met. About student faculty ratio $(15: 1)$, only $65 \%$ of students felt it was sufficient. The reason may be that the ratio was slightly higher in the beginning (21:1) and it was maintained adequately after their second block. Also all students may not be aware of the student faculty ratio which should be $18: 1$ and its importance in teaching learning process. 
The process of learning in the formal educational institutions is usually assessment driven (Abraham et al, 2005; Torke et al, 2008). At MMMC, to get promoted to next year, students have to be successful in practical examinations and theory. The practical examination includes two performance stations, wherein, they have to perform in-front of the examiners. These can be obvious reasons for their motivation to practice in laboratory sessions. One more reason for their interest could be because of small group teaching in LBL sessions, where student teacher interaction is better (Iputo J, Kwizera, 2005, Yvonne, 2004) compared to lecture classes. Also, students learn better in a small group by working together (Cohen, 1994). Occasionally, at the end of a practical class, students are asked to demonstrate/perform the particular experiment they have learnt during the session.

Students have not suggested any major changes in the conduction and delivery methodology for LBL sessions. On the other hand, faculty members came out with some very interesting suggestions such as, introducing digital learning, use of video clips, connecting the experiments to clinical scenarios. Faculty members also expressed that delivery methodology could be assessment driven to enhance learning.

\section{Conclusion}

The content and delivery in medical education is evolving globally and it is imperative for every medical college to adapt to changes. The way in which LBL sessions in physiology were designed and delivered at MMMC, Manipal was accepted by both students and faculty members. The majority of the respondents were satisfied with the current conduct of LBL sessions in physiology. The suggestions given by both students and faculty members show beyond any doubt, their interest and involvement in LBL sessions. It also shows their willingness to participate in any initiative aiming for improvements in LBL sessions. Most of the suggestions obtained from the study could be implemented with minimal efforts, while, some of them requires additional infrastructure and logistic support.

\section{Acknowledgements:}

We thank Jessica Sushma D'Souza, Department of Microbiology, MMMC, for her valuable suggestions; faculty members of physiology and students of March 2010 MBBS batch, Melaka Manipal Medical College, Manipal campus for their valuable feedback.

Figure 1: Student performance in the practical examination






\section{References:}

Abraham, R.R., Upadhya, S., Torke, S. \& Ramnarayan, K. (2005) Student perspectives of assessment by TEMM model in physiology, Adv Physiol Educ, 29, pp. 94-97.

Bates' S., Macleod, H. \& McCune, V. n.d. Introduction to practical classes, [Online], Available at: www.tla.ed.ac.uk/services/effectlearn/practical.pdf [Accessed 25 March 2011].

Caglayan, S. (1994) Effectiveness of an active method in teaching physiology, Adv Physiol Educ, 12, pp. S81-S86.

Cohen, E.G. (1994) Restructuring the classroom: Conditions for productive small groups, Rev Educational Res, 64, pp.1-35.

Croker, K., Anderson, H., Lush, D., Prince, R. \& Gomez, S. (2010) Enhancing the student experiencing of laboratory practicals through digital video guides [Online], Available at: www.bioscience.heacademy.ac.uk/journal/vol 16/beej-16-2.aspx [Accessed 25 March 2011].

Dantas, A.M. \& Kemm, R.E. (2008) A blended approach to active learning in a physiology laboratory-based subject facilitated by an elearning component, Adv Physiology Educ, 32, pp. 65-75.

Donnel, R.W. (2006) The importance of basic science in medical education, [Online], Available at: doctorrw.blogspot.com/.../importance-of-basicscience-in-medical.html [Accessed 25 March 2011].

Iputo, J. \& Kwizera, E. (2005) Problem-based learning improves the academic performance of medical students in South Africa, Medical Education, 39, pp. 388-393.
Lata, H. \& Walia, L. (2010) Appraisal \& improvisation of undergraduate practical curriculum in physiology, South East Asian Journal of Medical Education, 4, pp. 55-58.

Pal, G.K. \& Pal, P. (2001) Text book of practical physiology, Chennai: Orient Longman.

Prayoonwong, T. \& Nimnuan, C. (2010) Dental students' perceptions of learning environment, South-East Asian Journal of Medical Education, 4, pp. 49-54

Quinn, J. N.D., CEAIL Report on laboratory practicals, [Online], Available at: http://www.qub.ac.uk/sites/CentreforExcellence inActiveandInteractiveLearning/BioscienceProj ect/ActiveandInteractiveLearning/Fi [Accessed 25 March, 2011].

Rao, S.P. \& DiCarlo, S.E. (2001) Active learning of respiratory physiology improves performance on respiratory physiology examination, $A d v$ Physiol Educ, 25, pp. 55-61.

Torke, S., Upadhya, S., Abraham, R.R., Asha, K. \& Ramnarayan, K. (2008) Integrated practical examination: A novel approach to evaluate undergraduate medical students in physiology, South East Asian Medical Education, 2(1), pp. 48-54.

Wilson, A.B., Ross, C., Petty, M., Williams, J.M. \& Thorp, L.E. (2009) Bridging the transfer gap: laboratory exercise combines clinical exposure and anatomy review, Medical Education, 43, pp. 790-798.

Yvonne, S. (2004) Student perceptions of effective small group teaching, Medical Education, 38, pp. 286-293. 